\title{
Treadmill exercise activates PI3K/Akt signaling pathway leading to GSK-3 $\beta$ inhibition in the social isolated rat pups
}

\author{
Lin Ru Wang, Seung-Soo Baek* \\ Department of Sport \& Health Science, College of Natural Science, Sangmyung University, Seoul, Korea
}

Social isolation is known to precipitate depression-like symptoms in rodents and has emerged as a dependable paradigm to screen the behavioral and neurobiological changes observed in humans. In the present study, the undying mechanisms of treadmill exercise on social isolation-induced depression was evaluated. The rat pups in the social isolation groups were housed individually. The social isolation procedures started on the postnatal day 14. The rat pups in the exercise groups were forced to run on treadmill for 30 min once a day from postnatal day 21 to postnatal day 34 . The expression of phosphoinositide 3 kinase (PI3K), tyrosine kinase B (Akt), and glycogen synthase kinase $3 \beta$ (GSK$3 \beta$ ) in the hippocampus were determined by using western blot analysis. The ratio phosphorylated PI3K (p-PI3K)/PI3K and phosphorylated
Akt (p-Akt)/Akt were decreased and the ratio of phosphorylated-GSK-3 (p-GSK-3 $\beta$ )/GSK-3 $\beta$ was increased by social isolation. Treadmill exercise increased the ratio $p-P I 3 K / P I 3 K$ and $p$-Akt/Akt and suppressed the ratio of $p-G S K-3 \beta / G S K-3 \beta$ in the hippocampus of social isolated rat pups. Treadmill exercise activates PI3K/Akt signaling pathway leading to GSK$3 \beta$ inhibition in social isolated rats. These results suggested that treadmill exercise may improve depressive symptoms via activation of PI3K/ Akt signaling pathway.

Keywords: Social isolation, Treadmill exercise, Depression, PI3K, Akt, GSK-3 $\beta$

\section{INTRODUCTION}

Exposure to stress during the early stage of development exerts negative influence on brain development and stress is associated with psychological disorders, such as depression and anxiety (Fone and Porkess, 2008; Ladd et al., 2000). Among stressors, social isolation is known to precipitate depression-like symptoms (Baek et al., 2012; Dandekar et al., 2009).

The effectiveness of exercise for stress-related disorders, especially depression, is well documented (Lee and Baek, 2017). Physical exercise has an antidepressant action in animals and humans (Lawlor and Hopker, 2001; Santarelli et al., 2003). Cho et al. (2017) reported that treadmill exercise alleviated depression caused by social isolation by increasing hippocampal neurogenesis through serotonin upregulation.

Protein kinase B (Akt) is a member of a class of serine or threonine protein kinases, and is a major effector in the phosphoinos- itide 3 kinase (PI3K) signaling pathway (Brazil and Hemmings, 2001; Shiojima and Walsh, 2002). Akt has a significant role in multiple cellular processes, including cell survival, metabolism, growth, proliferation and mobility (Brazil and Hemmings, 2001). Akt also regulates vascular homeostasis and angiogenesis (Shiojima and Walsh, 2002).

Glycogen synthase kinase 3 (GSK-3) has two isoforms, GSK$3 \alpha$ and GSK-3 $\beta$, that are inactivated by Akt phosphorylation on Ser21 and Ser9, respectively (Cross et al., 1995). Inhibition of GSK-3 is known to protect apoptosis in many situations (Pap and Cooper, 1998). GSK-3 $\beta$ is a downstream target of Akt and activation of Akt inhibits GSK-3 $\beta$ by inducing its phosphorylation (Wu et al., 2007).

In the present study, the undying mechanisms of treadmill exercise on social isolation-induced depression was evaluated. We hypothesize that antidepressive effect of treadmill exercise might be mediated by GSK-3 $\beta$ inactivation through activation of the

\footnotetext{
*Corresponding author: Seung-Soo Baek (iD https://orcid.org/0000-0002-1340-2098 Department of Sport \& Health Science, College of Natural Science, Sangmyung University, 20 Hongjimun 2-gil, Jongno-gu, Seoul 03016, Korea Tel: +82-2-2287-5133, Fax: +82-2-2287-0075, E-mail: ssoop@smu.ac.kr Received: January 5, 2018 / Accepted: February 2, 2018
}

This is an Open Access article distributed under the terms of the Creative Commons Attribution Non-Commercial License (http://creativecommons.org/licenses/by-nc/4.0/) which permits unrestricted non-commercial use, distribution, and reproduction in any medium, provided the original work is properly cited. 
PI3K/Akt signaling pathway.

\section{MATERIALS AND METHODS}

\section{Animals and treatments}

On the postnatal day 14, the rat pups were divided into one of the four groups: the control group, the exercise group, the social isolation group, and the social isolation and exercise group $(\mathrm{n}=8$ in each group). The rat pups in the control group and exercise groups were housed with their respective mothers under standard conditions, while the rat pups in the social isolation groups were housed individually. The social isolation procedures started on the postnatal day 14 . The rat pups in the exercise groups were forced to run on treadmill for 30 min once a day from postnatal day 21 to postnatal day 34 . The exercise load consisted of running at a speed of $2 \mathrm{~m} / \mathrm{min}$ for the first $5 \mathrm{~min}$, at a speed of $5 \mathrm{~m} / \mathrm{min}$ for the next $5 \mathrm{~min}$, and then at a speed of $8 \mathrm{~m} / \mathrm{min}$ for the last $20 \mathrm{~min}$ with $0 \%$ grade of inclination.

\section{Tissue preparation}

After anesthetizing with Zoletil $50(10 \mathrm{mg} / \mathrm{kg}$ intraperitoneally; Vibac Laboratories, Carros, France), the rat pups were transcar- dially perfused with $50 \mathrm{mM}$ phosphate-buffered saline and subsequently fixed with freshly prepared $500 \mathrm{mM}$ phosphate buffer $(\mathrm{pH}, 7.4)$ containing $4 \%$ paraformaldehyde. The brains of the rat pups were removed and fixed in the same fixative overnight and then transferred into a 30\% sucrose solution for cryoprotection. Serial coronal sections of $40-\mu \mathrm{m}$ thickness were obtained using a freezing microtome (Leica, Nussloch, Germany).

\section{Western blot analysis}

Western blot analysis was performed according to the previous method (Cho et al., 2017; Kim et al., 2010). Protein separation was performed using $10 \%$ polyacrylamide with $0.05 \%$ bis-acrylamide. Proteins were then transferred to nitrocellulose and the blots were probed with anti-PI3K mouse monoclonal antibody (1:1,000; Santa Cruz Biotechnology, Santa Cruz, CA, USA), antip-PI3K rabbit polyclonal antibody (1:1,000; Santa Cruz Biotechnology), anti-Akt rabbit polyclonal antibody (1:1,000; Cell Signaling Technology Inc., Beverly, Massachusetts, USA), anti-p-Akt rabbit polyclonal antibody (1:1,000; Cell Signaling Technology), anti-GSK-3 $\beta$ rabbit polyclonal antibody $(1: 1,000$; Santa Cruz Biotechnology), and anti-p-GSK-3 $\beta$ rabbit polyclonal antibody (1:1,000; Santa Cruz Biotechnology). Peroxidase anti-rabbit IgG
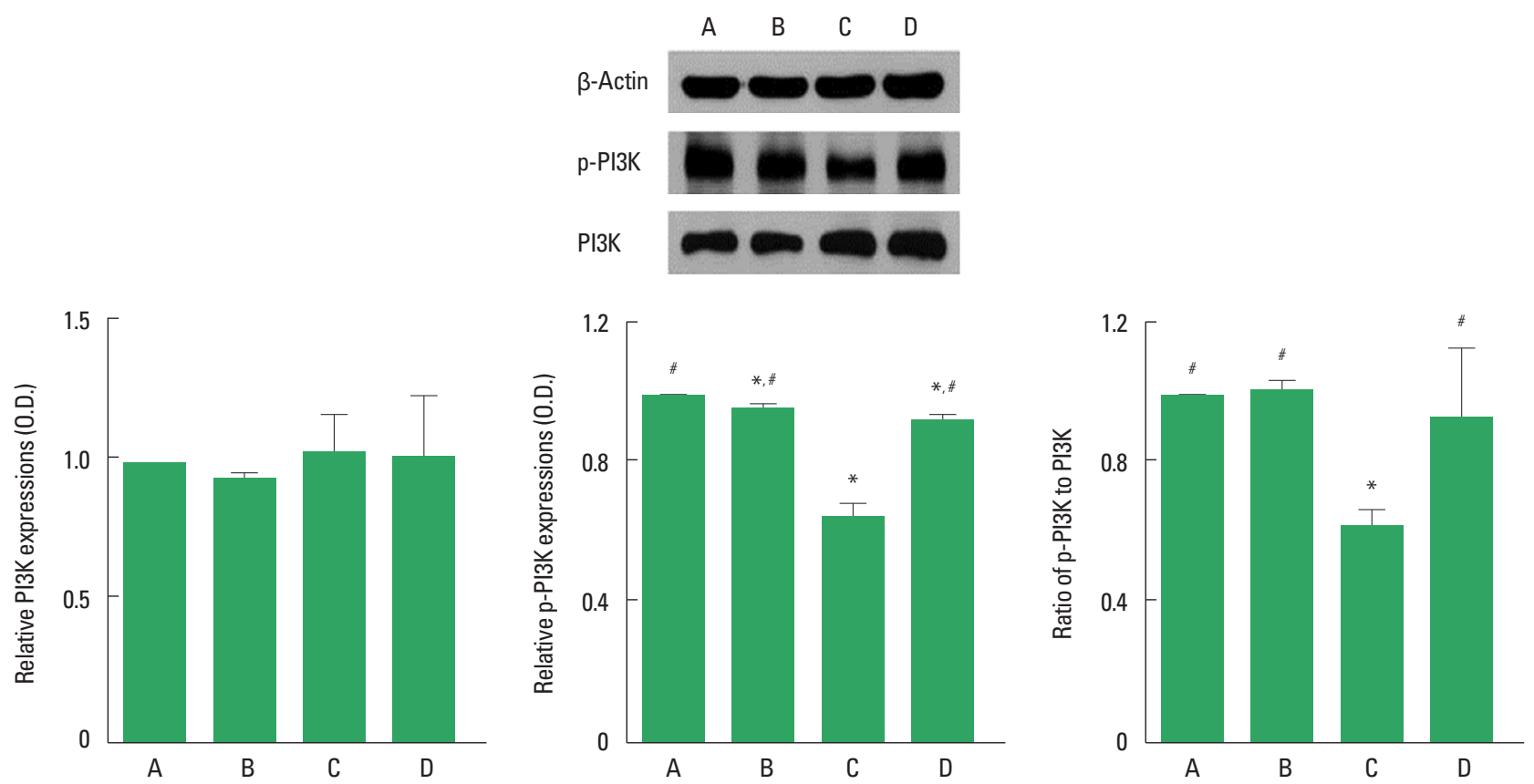

Fig. 1. Effect of treadmill exercise on phosphoinositide 3 kinase (PI3K) and phosphorylated PI3K (p-PI3K) expression in the hippocampus. Upper panel: representative expression of PI3K, p-PI3K, and $\beta$-actin. Lower panel: relative expression of PI3K, p-PI3K, and p-PI3K/PI3K ratio. Left panel: relative PI3K expression. Middle panel: relative $p-P \mid 3 K$ expression. Right panel: relative ratio of $p-P|3 K / P| 3 K$. The data are represented as the mean \pm standard error of the mean. $A$, control group; $B$, exercise group; $\mathrm{C}$, social isolation group; $\mathrm{D}$, social isolation and exercise group. ${ }^{*} P<0.05$ compared to the control group. ${ }^{\sharp} P<0.05$ compared to the social isolation group. 
(1:5,000; Vector Laboratories) and peroxidase anti-mouse IgG (1:10,000; Vector Laboratories) were used as the secondary antibodies. Immunoreactivity was detected by enhanced chemiluminescence (ECL) detection kit (Santa Cruz Biotechnology).

\section{Data analysis}

Differences among the groups were evaluated using IBM SPSS Statistics ver. 21.0 (IBM Co., Armonk, NY, USA) by the one-way analysis of variance followed by Duncan post hoc test. All values are expressed as the mean \pm standard error of the mean. Statistically significant differences were established at $P<0.05$.

\section{RESULTS}

\section{$\mathrm{PI} 3 \mathrm{~K}$ and p-PI3K expression in the hippocampus}

Western blot analysis for the expression of PI3K and p-PI3K in the hippocampus was performed (Fig. 1). Social isolation and treadmill exercise did not significantly affect PI3K expression in rat pups of all groups (Fig. 1, left panel). The expression of p-PI3K was decreased by social isolation. Treadmill exercise increased p-PI3K expression in the rat pups of social isolation group (Fig. 1, middle panel). The ratio of $\mathrm{p}-\mathrm{PI} 3 \mathrm{~K} / \mathrm{PI} 3 \mathrm{~K}$ was decreased by social isolation. Treadmill exercise increased the ratio of $\mathrm{p}-\mathrm{PI} 3 \mathrm{~K} / \mathrm{PI} 3 \mathrm{~K}$ in the rat pups of social isolation group by enhancing the expres- sion of p-PI3K (Fig. 1, right panel).

\section{Akt and p-Akt expression in the hippocampus}

Western blot analysis for the expression of Akt and p-Akt in the hippocampus was performed (Fig. 2). The expression of Akt was decreased by social isolation. Treadmill exercise increased Akt expression in the rat pups of social isolation group (Fig. 2, left panel). The expression of p-Akt was decreased by social isolation. Treadmill exercise increased $\mathrm{p}$-Akt expression in the rat pups of social isolation group (Fig. 2, middle panel). The ratio of p-Akt/ Akt was decreased by social isolation. Treadmill exercise increased the ratio of $\mathrm{p}-\mathrm{Akt} / \mathrm{Akt}$ in the rat pups of social isolation group by enhancing the expression of p-Akt (Fig. 2, right panel).

\section{GSK-3 $\beta$ and $p-$ GSK-3 $\beta$ expression in the hippocampus}

Western blot analysis for the expression of GSK-3 $\beta$ and p-GSK$3 \beta$ in the hippocampus was performed (Fig. 3). The expression of GSK-3 $\beta$ was decreased by treadmill exercise in both normal and social isolated group (Fig. 3, left panel). The expression of p-GSK$3 \beta$ was increased by social isolation. Treadmill exercise decreased p-GSK-3 $\beta$ expression in the rat pups of social isolation group (Fig. 3 , middle panel). The ratio of $\mathrm{p}-\mathrm{GSK}-3 \beta / \mathrm{GSK}-3 \beta$ was increased by social isolation. Treadmill exercise decreased the ratio of $\mathrm{p}-\mathrm{GSK}$ $3 \beta / G S K-3 \beta$ in the rat pups of social isolation group by suppress-
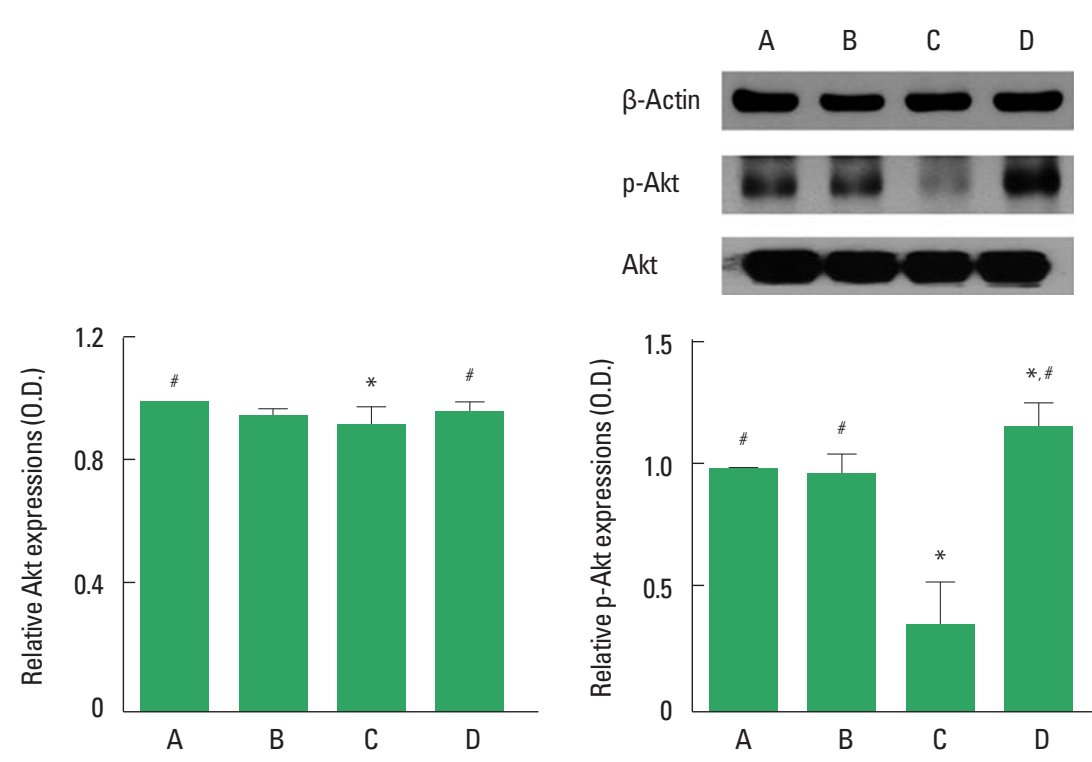

Fig. 2. Effect of treadmill exercise on protein kinase B (Akt) and phosphorylated Akt (p-Akt) expression in the hippocampus. Upper panel: representative expression of Akt, p-Akt, and $\beta$-actin. Lower panel: relative expression of Akt, p-Akt, and p-Akt/Akt ratio. Left panel: relative Akt expression. Middle panel: relative p-Akt expression. Right panel: relative ratio of $p$-Akt/Akt. The data are represented as the mean \pm standard error of the mean. $A$, control group; $B$, exercise group; $C$, social isolation group; $\mathrm{D}$, social isolation and exercise group. ${ }^{*} P<0.05$ compared to the control group. ${ }^{\sharp} P<0.05$ compared to the social isolation group. 


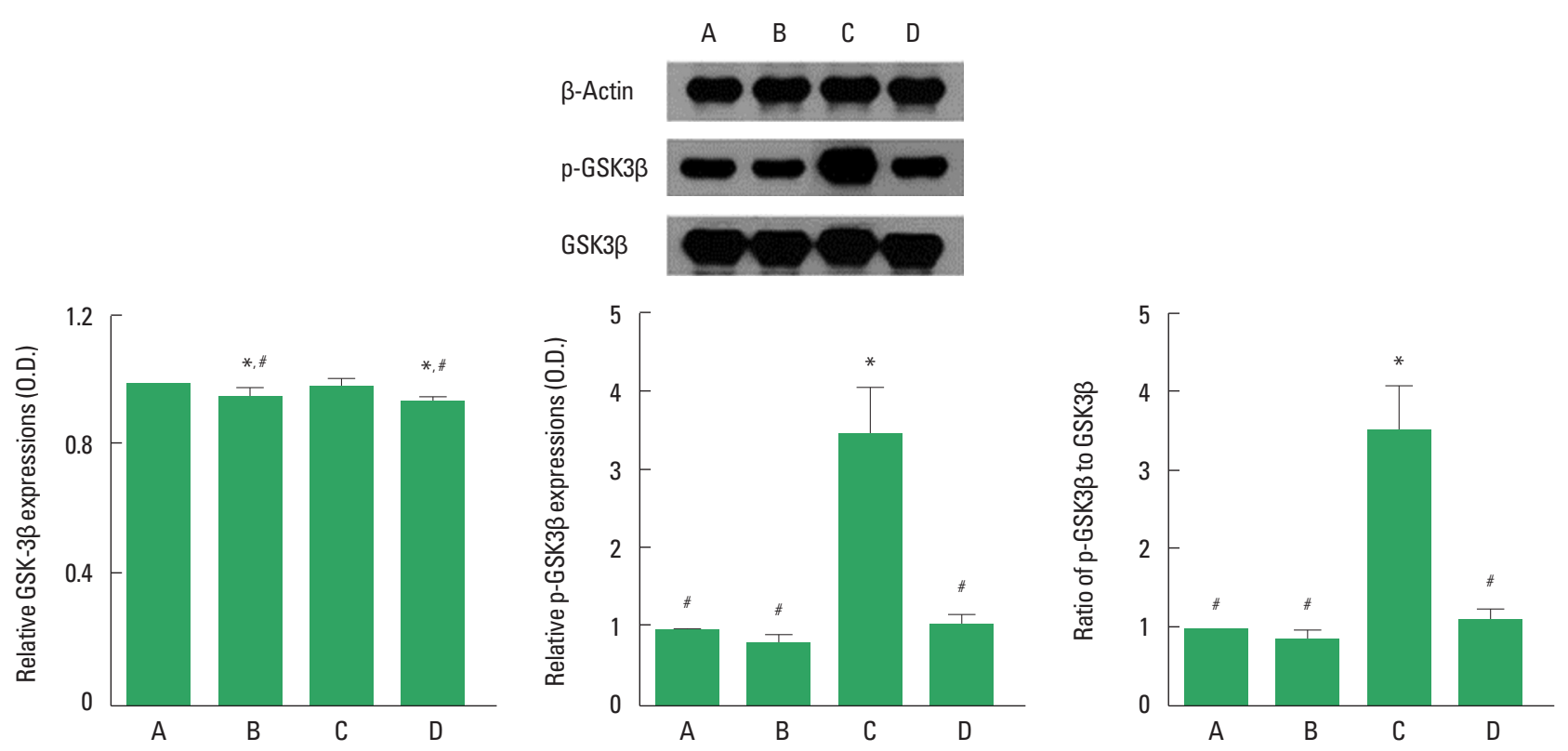

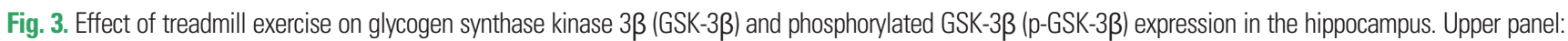

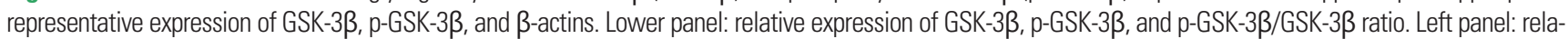

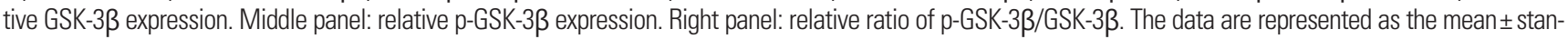
dard error of the mean. $A$, control group; $B$, exercise group; $C$, social isolation group; $D$, social isolation and exercise group. ${ }^{*} P<0.05$ compared to the control group. ${ }^{\#} P<0.05$ compared to the social isolation group.

ing the expression of p-GSK-3 $\beta$ (Fig. 3, right panel).

\section{DISCUSSION}

Activation of PI3K is the most important mechanism of promoting cell survival by neurotrophins (Vaillant et al., 1999). PI3K/ Akt pathway is implicated in the cell proliferation and migration during neurogenesis (Zhang et al., 2011). Activation of PI3K/Akt is a hallmark of cell survival/proliferation, and PI3K/Akt pathway is implicated in the protective role in many neuropathological conditions (Chavali et al., 2011). In the present study, the ratio of $\mathrm{p}-\mathrm{PI} 3 \mathrm{~K} / \mathrm{PI} 3 \mathrm{~K}$ in the hippocampus was decreased by social isolation. However, treadmill exercise restored the social isolation-induced decreased $\mathrm{p}-\mathrm{PI} 3 \mathrm{~K} / \mathrm{PI} 3 \mathrm{~K}$ ratio by enhancing the expression of $\mathrm{p}-\mathrm{PI} 3 \mathrm{~K}$. The present result showed that treadmill exercise exerted ameliorating effect on depression through the phosphorylation of $\mathrm{PI} 3 \mathrm{~K}$.

Akt promote neuronal differentiation (Vojtek et al., 2003), and neural progenitor cell proliferation is mediated by phosphorylation of Akt (Wu et al., 2009). Activation of Akt signaling in the endothelial cells stimulates endothelial cell bioactivity and angiogenesis (Kureishi et al., 2000). Phosphorylation of Akt is predominantly expressed in the diabetic retina (Wang et al., 2010). Akt phosphorylation is related to neurogenesis, and nuclear translocation of Akt is required for cell cycle progression (Parcellier et al., 2008). In the present study, the ratio of p-Akt/Akt in the hippocampus was decreased by social isolation, however, treadmill exercise increased the ratio of $\mathrm{p}-\mathrm{Akt} / \mathrm{Akt}$ by enhancing the expression of p-Akt. The present result showed that treadmill exercise exerted ameliorating effect on depression through the phosphorylation of Akt.

Akt is one of the kinases that inactivate GSK- $3 \beta$ via its phosphorylation. PI3K/Akt activation is linked to inhibition of GSK$3 \beta$ (Shaw et al., 1998). GSK-3 $\beta$ is one of the key targets of the well-established apoptotic signaling mediated by the PI3K/Akt pathway (Pap and Cooper, 1998). GSK-3 $\beta$ is a serine/threonine kinase mediating cellular signaling and cell death (Grimes and Jope, 2001). Selective inhibitors for GSK-3 $\beta$ showed antidepressant effect in the depression model (Kaidanovich-Beilin et al., 2004). GSK- $3 \beta$ is also important factor in both mood disorder and suicide behavior (Liu et al., 2012). In the present study, the expression of GSK- $3 \beta$ in the hippocampus was increased by social isolation. However, treadmill exercise decreased GSK- $3 \beta$ expression. The present results suggest that GSK-3 $\beta$ expression was suppressed by treadmill exercise through activation of PI3K/Akt signaling pathway. 
Lee and Baek (2017) suggested that exercise may preserve brain function by increasing neurogenesis in the psychiatric disorders, such as depression. Cho et al. (2017) also showed that treadmill exercise may ameliorates social isolation-induced depression through increasing neuronal generation.

Here in the present study, we have shown that treadmill exercise activates $\mathrm{PI} 3 \mathrm{~K} / \mathrm{Akt}$ signaling pathway leading to GSK-3 $\beta$ inhibition in social isolated rats. These results suggest that treadmill exercise may improve depressive symptoms via activation of $\mathrm{PI} 3 \mathrm{~K} /$ Akt signaling pathway.

\section{CONFLICT OF INTEREST}

No potential conflict of interest relevant to this article was reported.

\section{ACKNOWLEDGMENTS}

This work was supported by the Ministry of Education of the Republic of Korea and the National Research Foundation of Korea (NRF-2016S1A5A2A01026141).

\section{REFERENCES}

Baek SS, Jun TW, Kim KJ, Shin MS, Kang SY, Kim CJ. Effects of postnatal treadmill exercise on apoptotic neuronal cell death and cell proliferation of maternal-separated rat pups. Brain Dev 2012;34:45-56.

Brazil DP, Hemmings BA. Ten years of protein kinase B signalling: a hard Akt to follow. Trends Biochem Sci 2001;26:657-664.

Chavali PL, Saini RK, Matsumoto Y, Ågren H, Funa K. Nuclear orphan receptor TLX induces Oct-3/4 for the survival and maintenance of adult hippocampal progenitors upon hypoxia. J Biol Chem 2011;286:93939404.

Cho JW, Jung SY, Lee SW, Lee SJ, Seo TB, Kim YP, Kim DY. Treadmill exercise ameliorates social isolation-induced depression through neuronal generation in rat pups. J Exerc Rehabil 2017;13:627-633.

Cross DA, Alessi DR, Cohen P, Andjelkovich M, Hemmings BA. Inhibition of glycogen synthase kinase-3 by insulin mediated by protein kinase B. Nature 1995;378:785-789.

Dandekar MP, Singru PS, Kokare DM, Subhedar NK. Cocaine- and amphetamine-regulated transcript peptide plays a role in the manifestation of depression: social isolation and olfactory bulbectomy models reveal unifying principles. Neuropsychopharmacology 2009;34:12881300.

Fone KC, Porkess MV. Behavioural and neurochemical effects of post-wean- ing social isolation in rodents-relevance to developmental neuropsychiatric disorders. Neurosci Biobehav Rev 2008;32:1087-1102.

Grimes CA, Jope RS. The multifaceted roles of glycogen synthase kinase 3beta in cellular signaling. Prog Neurobiol 2001;65:391-426.

Kaidanovich-Beilin O, Milman A, Weizman A, Pick CG, Eldar-Finkelman $H$. Rapid antidepressive-like activity of specific glycogen synthase kinase-3 inhibitor and its effect on beta-catenin in mouse hippocampus. Biol Psychiatry 2004;55:781-784.

Kim SE, Ko IG, Kim BK, Shin MS, Cho S, Kim CJ, Kim SH, Baek SS, Lee EK, Jee YS. Treadmill exercise prevents aging-induced failure of memory through an increase in neurogenesis and suppression of apoptosis in rat hippocampus. Exp Gerontol 2010;45:357-365.

Kureishi Y, Luo Z, Shiojima I, Bialik A, Fulton D, Lefer DJ, Sessa WC, Walsh $\mathrm{K}$. The HMG-CoA reductase inhibitor simvastatin activates the protein kinase Akt and promotes angiogenesis in normocholesterolemic animals. Nat Med 2000;6:1004-1010.

Ladd CO, Huot RL, Thrivikraman KV, Nemeroff CB, Meaney MJ, Plotsky PM. Long-term behavioral and neuroendocrine adaptations to adverse early experience. Prog Brain Res 2000;122:81-103.

Lawlor DA, Hopker SW. The effectiveness of exercise as an intervention in the management of depression: systematic review and meta-regression analysis of randomised controlled trials. BMJ 2001;322:763-767.

Lee HJ, Baek SS. Role of exercise on molecular mechanisms in the regulation of antidepressant effects. J Exerc Rehabil 2017;13:617-620.

Liu R, Dang W, Jianting M, Su C, Wang H, Chen Y, Tan Q. Citalopram alleviates chronic stress induced depression-like behaviors in rats by activating GSK3 $\beta$ signaling in dorsal hippocampus. Brain Res 2012;1467: 10-17.

Pap M, Cooper GM. Role of glycogen synthase kinase-3 in the phosphatidylinositol 3-Kinase/Akt cell survival pathway. J Biol Chem 1998;273: 19929-19932.

Parcellier A, Tintignac LA, Zhuravleva E, Hemmings BA. PKB and the mitochondria: AKTing on apoptosis. Cell Signal 2008;20:21-30.

Santarelli L, Saxe M, Gross C, Surget A, Battaglia F, Dulawa S, Weisstaub N, Lee J, Duman R, Arancio O, Belzung C, Hen R. Requirement of hippocampal neurogenesis for the behavioral effects of antidepressants. Science 2003;301:805-809.

Shaw M, Cohen P, Alessi DR. The activation of protein kinase $\mathrm{B}$ by $\mathrm{H} 2 \mathrm{O} 2$ or heat shock is mediated by phosphoinositide 3-kinase and not by mitogen-activated protein kinase-activated protein kinase-2. Biochem J 1998;336(Pt 1):241-246.

Shiojima I, Walsh K. Role of Akt signaling in vascular homeostasis and angiogenesis. Circ Res 2002;90:1243-1250.

Vaillant AR, Mazzoni I, Tudan C, Boudreau M, Kaplan DR, Miller FD. Depolarization and neurotrophins converge on the phosphatidyli- 
nositol 3-kinase-Akt pathway to synergistically regulate neuronal survival. J Cell Biol 1999;146:955-966.

Vojtek AB, Taylor J, DeRuiter SL, Yu JY, Figueroa C, Kwok RP, Turner DL. Akt regulates basic helix-loop-helix transcription factor-coactivator complex formation and activity during neuronal differentiation. Mol Cell Biol 2003;23:4417-4427.

Wang Q, Pfister F, Dorn-Beineke A, vom Hagen F, Lin J, Feng Y, Hammes HP. Low-dose erythropoietin inhibits oxidative stress and early vascular changes in the experimental diabetic retina. Diabetologia 2010; 53:1227-1238.
Wu Y, Peng H, Cui M, Whitney NP, Huang Y, Zheng JC. CXCL12 increases human neural progenitor cell proliferation through Akt-1/FOXO3a signaling pathway. J Neurochem 2009;109:1157-1167.

Wu Y, Shang Y, Sun S, Liang H, Liu R. Erythropoietin prevents PC12 cells from 1-methyl-4-phenylpyridinium ion-induced apoptosis via the Akt/ GSK-3beta/caspase-3 mediated signaling pathway. Apoptosis 2007;12: 1365-1375.

Zhang Q, Liu G, Wu Y, Sha H, Zhang P, Jia J. BDNF promotes EGF-induced proliferation and migration of human fetal neural stem/progenitor cells via the PI3K/Akt pathway. Molecules 2011;16:10146-10156. 